\title{
IMPLEMENTASI MANAJEMEN PENGETAHUAN DI PERPUSTAKAAN UIN SUNAN KALIJAGA YOGYAKARTA
}

\author{
Thoriq Tri Prabowo ${ }^{1}$ \\ ${ }^{1}$ Fakultas Sains dan Teknologi UIN Sunan Kalijaga \\ ${ }^{1}$ thoriq.prabowo@uin-suka.ac.id
}

ABSTRACT - This research is aim to understanding the level of UIN Sunan Kalijaga Library in implementing knowledge management. This type of research is a quantitative descriptive. This research is a population research, because it engages all of UIN Sunan Kalijaga Librarians as the respondents. Total of the respondents are 21 librarians. To collect the data the researcher uses the questionnaire, and also uses the nonparticipant observation, interviews, and the documentation to understand deeper abou the research object. Likert scale is used to measure the data, the researcher uses mean and grand mean formulas to analyze the data. The result of the research shows that the level of UIN Sunan Kalijaga Library in implementing knowledge management is high. But, from the this research also understood that there is an indicator need to be increased because the score is lower than the mean, it is "learning" indicator. One of interesting phenomena is about the librarians education background. The librarians which graduated from non library and information science (LIS) could implement knowledge management better than the librarians which graduated from LIS.

Keywords: Knowledge management, librarian competence, academic library, UIN Sunan Kalijaga Library

ABSTRAK - Penelitian ini bertujuan untuk mengetahui sejauh mana tingkat implementasi manajemen pengetahuan yang dilakukan oleh pustakawan di Perpustakaan UIN Sunan Kalijaga. Penelitian ini merupakan penelitian deskriptif kuantitatif. Populasi dalam penelitian ini adalah seluruh pustakawan di Perpustakaan UIN Sunan Kalijaga. Penelitian ini merupakan penelitian populasi karena jumlah populasinya hanya 21 orang. Metode pengumpulan data menggunakan kuesioner. Untuk mengetahui lebih dalam kondisi di lapangan digunakan juga observasi nonpartisipatif, wawancara dan dokumentasi. Pengukuran data dalam penelitian ini menggunakan skala likert. Analisis data dalam penelitian ini merupaan analisis deskriptif, yaitu menggunakan mean dan grand mean. Hasil penelitian menunjukkan bahwa: Impementasi manajemen pengetahuan di Perpustakaan UIN Sunan Kalijaga masuk dalam tingkat yang tinggi. Dari hasil penelitian ada beberapa indikator yang perlu ditingkatkan, yaitu indikator yang memperoleh skor di bawah rata-rata yaitu indikator learning. Salah satu temuan yang menarik adalah tingkat implementasi manajemen pengetahuan pustakawan yang berlatar belakang pendidikan formal Ilmu Perpustakaan dan Informasi (IPI) justru lebih rendah daripada pustakawan yang bukan berlatar belakang pendidikan formal Ilmu Perpustakaan dan Informasi (IPI).

Kata Kunci: Manajemen pengetahuan, kompetensi pustakawan, perpustakaan perguruan tinggi, Perpustakaan UIN Sunan Kalijaga.

\section{PENDAHULUAN}

Organisasi merupakan kumpulan dari beberapa individu yang diorganisir untuk mencapai tujuan tertentu. Perpustakaan juga merupakan sebuah organisasi yang memiliki pustakawan, kemudian diorganisir dengan harapan bisa mencapai tujuannya. Menurut Purwono tujuan utama dari berdirinya perpustakaan adalah menyediakan akses informasi kepada pemustaka (Purwono, 2013). Sulistyo-Basuki mendefinisikan perpustakaan sebagai sebuah ruangan, bagian dari ruangan atau gedung yang digunakan untuk menyimpan buku dan terbitan lainnya secara sistematis untuk kemudian dilayankan kepada pemustaka (Basuki, 
1991). Dari kedua pernyataan di atas bisa dipahami bahwa perpustakaan merupakan sebuah organisasi yang berorientasi pada pelayanan informasi.

Menurut Sulistyo-Basuki pelayanan yang diberikan perpustakaan adalah pelayanan yang bersifat nonprofit oriented, artinya perpustakaan tidak bertujuan memperoleh keuntungan komersial atas pelayanan yang diberikan tersebut (Basuki, 1991). Meskipun pelayanannya bersifat nonprofit oriented, perpustakaan harus mampu memberikan pelayanan informasi yang baik kepada pemustakanya. Perpustakaan diharapkan bisa turut mendukung amanat pembukaan Undang-Undang Dasar 1945, yaitu mencerdaskan kehidupan Bangsa.

Pelayanan seringkali menjadi tolok ukur pemustaka dalam menilai kualitas perpustakaan, karena pada bagian tersebut pustakawan langsung berinteraksi dengan pemustaka. Pustakawan sebagai orang yang bertanggung jawab atas terlaksananya pelayanan harus mengetahui hal tersebut. Pelayanan yang diberikan pustakawan berbanding lurus dengan kepuasan pemustaka (Akli, 2012). Oleh karena itu jika ingin mengingkatkan kepuasan pemustaka, maka syarat mutlaknya adalah dengan meningkatkan kualitas pelayanan.

Seringkali pemustaka mengeluhkan pelayanan yang kurang maksimal, dibuktikan dengan salah satu hasil penelitian Ralph yang menyatakan bahwa keakuratan pustakawan dalam memberikan pelayanan hanya 45\% (Ralph, 2008). Meskipun penelitian yang dilakukan tersebut dilakukan hanya pada bagian pelayanan referensi, tetapi hal tersebut tetap membuat pemustaka kecewa dan tidak puas akan pelayanan yang diberikan. Jika permasalahan yang demikian tidak ditindaklanjuti, maka perpustakaan akan sulit mencapai tujuannya.

Permasalahan yang dihadapi pemustaka dalam mengakses informasi di perpustakaan relatif sama, hanya saja karena pengetahuan di antara pustakawan yang berbeda-beda, maka penanganannya pun relatif berbeda-beda sehingga pemustaka merasa tidak puas akan pelayanan tersebut. Setiap pustakawan akan mampu memberikan pelayanan informasi yang maksimal, jika dalam menyelesaikan permasalahan yang dihadapi pemustaka para pustakawan saling berbagi pengetahuan yang dimiliki (Rodin, Penerapan Knowledge Management di Perpustakaan: Studi Kasus di Perpustakaan STAIN Curup, 2013).

Perpustakaan UIN Sunan Kalijaga Yogyakarta merupakan perpustakaan pertama yang menggunakan teknologi RFID dalam data Rekor MURI (Hadna, 2014). Berdasarkan hasil wawancara peneliti dengan ketua kelompok pustakawan Perpustakaan UIN Sunan Kalijaga, diketahui bahwa prestasi yang demikian tentu tidak diraih dengan begitu saja, melainkan didukung oleh kompetensi pustakawan dan manajemen organisasi yang baik.

Prestasi yang didapatkan oleh Perpustakaan UIN Sunan Kalijaga Yogyakarta didapatkan karena adanya koordinasi yang baik dari pimpinan, kerjasama setiap pustakawan, dukungan teknologi, dan fasilitas memadai yang disediakan oleh perpustakaan. Perpustakaan UIN 
Sunan Kalijaga Yogyakarta berupaya mempertahankan dan meningkatkan prestasinya dengan menjaga koordinasi di antara pustakawan melalui rapat rutin, seminar dan pelatihan, serta menyediakan dukungan teknologi informasi yang memadai dalam menunjang hubungan antar pustakawan dan pelayanan perpustakaan.

\section{Berdasarkan data kepegawaian}

Perpustakaan UIN Sunan Kalijaga Yogyakarta, diketahui bahwa jenjang pendidikan pustakawan berbeda-beda. Dari ke-21 pustakawan, hanya 8 pustakawan yang berlatar belakang pendidikan formal Ilmu Perpustakaan dan Informasi. Sedangkan yang lain menjadi pustakawan melalui jalur Empashing dan CPTA. LSP (Lembaga Sertifikasi Pustakawan) mengungkapkan bahwa aspek pengetahuan dalam kompetensi pustakawan sebagai sebuah profesi diperoleh melalui pendidikan formal. Pernyataan tersebut sesuai dengan Standar Nasional Perpustakaan (SNP 010:2011) poin 2.13 yang mengungkapkan bahwa pendidikan pustakawan perguruan tinggi serendah-rendahnya adalah sarjana di bidang ilmu perpustakaan dan informasi. Selain itu, berdasarkan hasil wawancara dengan beberapa pustakawan di Perpustakaan UIN Sunan Kalijaga Yogyakarta diketahui bahwa banyak pustakawan yang tidak bisa memanfaatkan teknologi seperti media sosial dan instant messenger untuk berbagi pengetahuan.

Perbedaan latar pendidikan pustakawan, antara pustakawan yang berlatar belakang pendidikan Ilmu Perpustakaan dan Informasi dan nonIlmu Perpustakaan dan Informasi serta rendahnya kemampuan pustakawan untuk menggunakan teknologi dikhawatirkan menimbulkan gap/jenjang pengetahuan, sehingga menjadikan proses implementasi manajemen pengetahuan terhambat. Jika melihat salah satu manfaat manajemen pengetahuan adalah menunjang peningkatkan kompetensi sumber daya manusia. Dikhawatirkan gap/jenjang pengetahuan tersebut berpengaruh buruk pada kompetensi pustakawan.

Penelitian ini bertujuan untuk mengetahui seberapa jauh implementasi pengetahuan yang dilaksanakan, meskipun diketahui juga terdapat beberapa kendala. Berdasarkan pemaparan latar belakang di atas, maka yang menjadi pertanyaan dalam penelitian ini adalah, Bagaimana tingkat implementasi manajemen pengetahuan yang dilakukan pustakawan di Perpustakaan UIN Sunan Kalijaga Yogyakarta?. Penelitian ini bertujuan untuk mengukur sejauhmana implementasi manajemen pengetahuan yang dilakukan oleh Pustakawan di Perpustakaan UIN Sunan Kalijaga Yogyakarta. Diharapkan hasil penelitian ini bisa menjadi bahan evaluasi untuk proses implementasi manajemen pengatahuan pustakawan agar Perpustakaan UIN Sunan Kalijaga Yogyakarta mampu memberikan pelayanan informasi yang baik kepada pemustakanya.

\section{TINJAUAN PUSTAKA}

Pengetahuan menjadi kunci untuk menyelesaikan sebuah permasalahan. Sehingga sangat penting bagi sebuah perpustakaan untuk mengorganisir pengetahuan. Pengetahuan dalam sebuah organisasi perlu dibagi karena pengetahuan dari masing-masing orang berbeda. Pentingnya mengorganisir pengetahuan, menjadikan pustakawan harus memahami manajemen pengetahuan. 
Menurut Lumbantobing, manajemen pengetahuan adalah serangkaian kegiatan mengorganisir sumber daya pengetahuan dari masing-masing individu yang ada di dalam sebuah organisasi untuk mencapai tujuannya (Lumbantobing, 2011). Ada banyak kegiatan yang bisa menimbulkan budaya berbagi pengetahuan dalam sebuah organisasi, misal diskusi baik menggunakan media konvensional maupun menggunakan bantuan teknologi, misal: media sosial dan instant messenger (Kurniawati, 2012), selain itu rapat rutin dan sistem rolling atau rotasi pegawai juga bisa meningkatkan budaya berbagi pengetahuan.

Kegiatan tersebut akan menjadikan pustakawan terus belajar untuk memahami segala aspek pekerjaan. Dengan membudayakan berbagi pengetahuan, maka diharapkan pekerjaan di perpustakaan akan dikerjakan dengan efektif dan efisien. Pada dasarnya manajemen pengetahuan melekat pada semua organisasi (Aldi, 2005). Tidak terkecuali perpustakaan, karena perpustakaan termasuk sebuah organisasi. Sejalan dengan Aldi, Rodin mengungkapkan bahwa manajemen pengetahuan di perpustakaan merupakan aktivitas keseharian perpustakaan (Rodin, Penerapan Knowledge Management di Perpustakaan: Studi Kasus di Perpustakaan STAIN Curup, 2013). Perpustakaan UIN Sunan Kalijaga Yogyakarta merupakan perpustakaan yang cukup berprestasi, terbukti dengan diraihnya akreditasi A dari Perpustakaan Nasional Republik Indonesia. Perpustakaan UIN Sunan Kalijaga Yogyakarta Yogyakarta juga sering dijadikan lokasi studi banding dari beberapa perpustakaan.

\section{METODE PENELITIAN}

Penelitian ini termasuk jenis penelitian deskriptif kuantitatif. Populasi dalam penelitian ini adalah seluruh pustakawan UIN Sunan Kalijaga Yogyakarta yang berjumlah 21 orang. Pengumpulan data dilakukan dengan menyebarkan kuesioner. Sedangkan untuk data tambahan dilakukan dengan wawancara dan observasi nonpartisipatif. Kuesioner dibuat dengan menganalisis indikator-indikator manajemen pengetahuan berdasarkan teori yang ada. Di bawah ini adalah tabel variabel dan indikator yang digunakan untuk menyusun kuesioner.

Tabel 1.Variabel \& Indikator Manajemen Pengetahuan

\begin{tabular}{|l|l|l|}
\hline Variabel & \multicolumn{1}{|c|}{ Indikator } & \multicolumn{1}{|c|}{$\begin{array}{c}\text { No. } \\
\text { Pernyataan }\end{array}$} \\
\hline Implementasi & 1. Manusia & $1 \& 2$ \\
manajemen & 2. Leadership & $7,5,8,9, \& 10$ \\
pengetahuan & 3. Teknologi & $11,12,13, \&$ \\
& 4. Organisasi & 14 \\
& 5. Learning & $15,16,17,18$ \\
& & $\& 19$ \\
\hline
\end{tabular}

Sumber: (Lumbantobing, 2011)

Tabel 2. Indikator dan Pernyataan Penelitian

\begin{tabular}{|c|c|c|}
\hline No & Indikator & Pernyataan \\
\hline 1 & \multirow[t]{2}{*}{ Manusia } & $\begin{array}{l}\text { Saya bekerja sesuai dengan } \\
\text { tugas yang diberikan kepada } \\
\text { saya }\end{array}$ \\
\hline 2 & & $\begin{array}{l}\text { Saya diberikan kesempatan } \\
\text { untuk mengatakan pendapat } \\
\text { saya pada saat rapat }\end{array}$ \\
\hline 3 & \multirow[b]{3}{*}{ Leadership } & $\begin{array}{l}\text { Pimpinan saya menyadari } \\
\text { bahwa berbagi pengetahuan } \\
\text { adalah hal yang penting }\end{array}$ \\
\hline 4 & & $\begin{array}{l}\text { Pimpinan saya sering membuka } \\
\text { forum untuk dialog pustakawan }\end{array}$ \\
\hline 5 & & $\begin{array}{l}\text { Pimpinan saya memberikan } \\
\text { motivasi kepada bawahan untuk } \\
\text { aktif dalam berbagi }\end{array}$ \\
\hline
\end{tabular}




\begin{tabular}{|c|c|c|}
\hline & & pengetahuan \\
\hline 6 & & $\begin{array}{l}\text { Pimpinan saya memberikan } \\
\text { kebebasan bagi bawahan untuk } \\
\text { mengekspresikan kreativitasnya }\end{array}$ \\
\hline 7 & \multirow{4}{*}{ Teknologi } & $\begin{array}{l}\text { Saya mampu mengoperasikan } \\
\text { teknologi informasi yang bisa } \\
\text { digunakan untuk berkomunikasi } \\
\text { dan berbagi pengetahuan antar } \\
\text { pustakawan }\end{array}$ \\
\hline 8 & & $\begin{array}{l}\text { Saya mendapatkan hak yang } \\
\text { sama untuk mengakses } \\
\text { teknologi informasi yang ada }\end{array}$ \\
\hline 9 & & $\begin{array}{l}\text { Saya memanfaatkan grup media } \\
\text { sosial untuk memudahkan } \\
\text { berdiskusi dengan pustakawan } \\
\text { yang lain }\end{array}$ \\
\hline 10 & & $\begin{array}{l}\text { Saya memanfaatkan instant } \\
\text { messenger (Contoh: Whatsapp, } \\
\text { BBM, Wechat, Line dan } \\
\text { lainnya) untuk memudahkan } \\
\text { berdiskusi dengan pustakawan } \\
\text { yang lain }\end{array}$ \\
\hline 11 & \multirow{4}{*}{ Organisasi } & $\begin{array}{l}\text { Adanya kebijakan institusi yang } \\
\text { mendukung program diskusi } \\
\text { rutin untuk pustakawan }\end{array}$ \\
\hline 12 & & $\begin{array}{l}\text { Adanya kesadaran institusi } \\
\text { untuk mengikuti tren dan } \\
\text { perkembangan positif yang ada } \\
\text { di dunia perpustakaan }\end{array}$ \\
\hline 13 & & $\begin{array}{l}\text { Adanya fasilitas yang memadai } \\
\text { yang disediakan institusi untuk } \\
\text { mendukung program diskusi }\end{array}$ \\
\hline 14 & & $\begin{array}{l}\text { Adanya penghargaan yang } \\
\text { diberikan institusi kepada } \\
\text { pustakawan yang berprestasi }\end{array}$ \\
\hline 15 & \multirow{5}{*}{ Learning } & $\begin{array}{l}\text { Penyelesaian masalah yang ada } \\
\text { di institusi diselesaikan secara } \\
\text { sistematis, yaitu dengan } \\
\text { melibatkan seluruh pustakawan }\end{array}$ \\
\hline 16 & & $\begin{array}{l}\text { Institusi tidak ragu-ragu untuk } \\
\text { mencoba penyelesaian masalah } \\
\text { dengan metode yang baru }\end{array}$ \\
\hline 17 & & $\begin{array}{l}\text { Dalam menyelesaikan masalah, } \\
\text { institusi bercermin pada } \\
\text { permasalahan yang pernah ada } \\
\text { sebelumnya }\end{array}$ \\
\hline 18 & & $\begin{array}{l}\text { Institusi aktif menyelesaikan } \\
\text { masalah dengan praktik-praktik } \\
\text { terbaik yang pernah dilakukan } \\
\text { institusi lain }\end{array}$ \\
\hline 19 & & $\begin{array}{l}\text { Adanya sistem rotasi } \\
\text { pustakawan yang bertujuan agar } \\
\text { pustakawan memahami seluruh } \\
\text { pekerjaan yang ada }\end{array}$ \\
\hline
\end{tabular}

Sumber: (Lumbantobing, 2011)

\section{HASIL DAN PEMBAHASAN}

Metode pengukuran data yang digunakan dalam penelitian ini adalah Skala Likert skala 1 (skor terendah) sampai dengan 5 (skor tertinggi), dan dibuat dalam bentuk checklist. Berdasarkan pada jawaban kuesioner yang diberikan kepada responden, rumus analisis yang digunakan untuk mengetahui tingkat impelementasi manajemen pengetahuan dilakukan perhitungan menggunakan rumus mean (rata-rata). Lalu penyajian data akan ditampilkan dengan tabel. Simamora mengungkapkan bahwa untuk mencari rentang skala dari jawaban responden menggunakan rumus di bawah ini (Simamora, 2008):

\section{Keterangan:}

$\mathrm{RS}=$ Rentang Skala $\mathrm{m}=$

\section{Skor tertinggi}

$\mathrm{n}=$ Skor terendah

$\mathrm{b}=$ Skala penilaian

Maka perhitungan rentang skalanya sebagai berikut.

$$
\begin{aligned}
& \mathrm{RS}=\frac{m-n}{b} \\
& R S=\frac{m-n}{b} \\
& R S=\frac{4}{5} \\
& R S=\frac{5-1}{5}
\end{aligned}
$$

$\mathrm{RS}=0,80$

Sehingga rentang skalanya adalah 0,80, dengan rentang skala 0,80 kemudian dibuat skala penilaian sebagai berikut: 
$1,00-1,80=$ Sangat Rendah

$1,80-2,60=$ Rendah

$2,60-3,40=$ Sedang

$3,40-4,20=$ Tinggi

$4,20-5,00=$ Sangat Tinggi

Untuk mengetahui tingkat implementasi manajemen pengetahuan yang dilakukan pustakawan di Perpustakaan UIN Sunan Kalijaga Yogyakarta, maka jawaban dari responden akan diuraikan dalam bentuk tabel, lalu dihitung menggunakan rumus mean dan grand mean. Nilai grand mean akan disajikan dalam bentuk tabel, yaitu dengan cara mengelompokkan masing- masing pernyataan ke dalam kelompok indikatornya. Di bawah ini adalah hasil analisis deskriptif menggunakan rumus mean dan grand mean dari indikator - indikator implementasi manajemen pengetahuan di Perpustakaan UIN Sunan Kalijaga Yogyakarta:

Tabel 3. Mean dan Grand Mean Analisis Deskriptif Indikator dan Variabel Implementasi Manajemen Pengetahuan di Perpustakaan UIN Sunan Kalijaga Yogyakarta

\begin{tabular}{|c|c|c|c|c|}
\hline $\begin{array}{l}\text { No } \\
\text {. }\end{array}$ & $\begin{array}{c}\text { Me } \\
\text { an }\end{array}$ & $\begin{array}{l}\text { Indikat } \\
\text { or }\end{array}$ & $\begin{array}{c}\text { Grand } \\
\text { Mean } \\
\text { Indika } \\
\text { tor }\end{array}$ & $\begin{array}{c}\text { Gran } \\
d \\
\text { Mean } \\
\text { Varia } \\
\text { bel }\end{array}$ \\
\hline 1 & 4,000 & \multirow[t]{2}{*}{ Manusia } & \multirow[t]{2}{*}{4,095} & \multirow[t]{5}{*}{3,958} \\
\hline 2 & 4,190 & & & \\
\hline 3 & 4,238 & \multirow{3}{*}{$\begin{array}{c}\text { Leadershi } \\
p\end{array}$} & \multirow{3}{*}{4,131} & \\
\hline 4 & 4,190 & & & \\
\hline 5 & 4,095 & & & \\
\hline
\end{tabular}

\begin{tabular}{|c|c|c|c|}
\hline 6 & 4,000 & & \\
\hline 7 & 3,809 & \multirow{5}{*}{ Teknologi } & \multirow{5}{*}{3,869} \\
\hline . & 1112 & & \\
\hline 8 & 4,143 & & \\
\hline 9 & 3,857 & & \\
\hline 10. & 3,666 & & \\
\hline 11. & 4,000 & \multirow{4}{*}{$\underset{\mathrm{i}}{\text { Organisas }}$} & \multirow{4}{*}{3,893} \\
\hline 12. & 3,952 & & \\
\hline 13. & 4,000 & & \\
\hline 14. & 3,619 & & \\
\hline 15. & 3,571 & \multirow{5}{*}{ Learning } & \multirow{5}{*}{3,800} \\
\hline 16. & 3,714 & & \\
\hline 17. & 3,762 & & \\
\hline 18. & 3,762 & & \\
\hline 19. & 4,190 & & \\
\hline
\end{tabular}

Sumber: Analisis Hasil Lapangan

Dari tabel dan grafik di atas bisa diketahi bahwa indikator "manusia" mendapatkan hasil 4,095 yang berada pada rentang 3,40 - 4,20 yang berarti memperoleh penilaian yang tinggi. Selanjutnya indikator leadership mendapatkan hasil 4,131 yang berada pada rentang 3,40 - 4,20 yang berarti memperoleh penilaian yang tinggi.

Indikator "teknologi" mendapatkan hasil 3,869 yang berada pada rentang 3,40 - 4,20 yang berarti mem- peroleh penilaian yang tinggi. Indikator "organisasi" mendapatkan hasil 3,893 yang berada pada rentang 3,40 - 4,20 yang berarti memperoleh penilaian yang tinggi, dan yang terakhir indikator "learning" mendapatkan hasil 3,800 yang berada pada rentang 3,40 - 4,20 yang berarti memperoleh penilaian yang tinggi. Setelah dilakukan perhitungan menggunakan rumus grand mean diketahui bahwa implementasi 
manajemen pengetahuan di Perpustakaan UIN Sunan Kalijaga Yogyakarta mendapatkan hasil mean 3,958 yang berada pada rentang 3,40 - 4,20 yang berarti memperoleh penilaian yang tinggi.

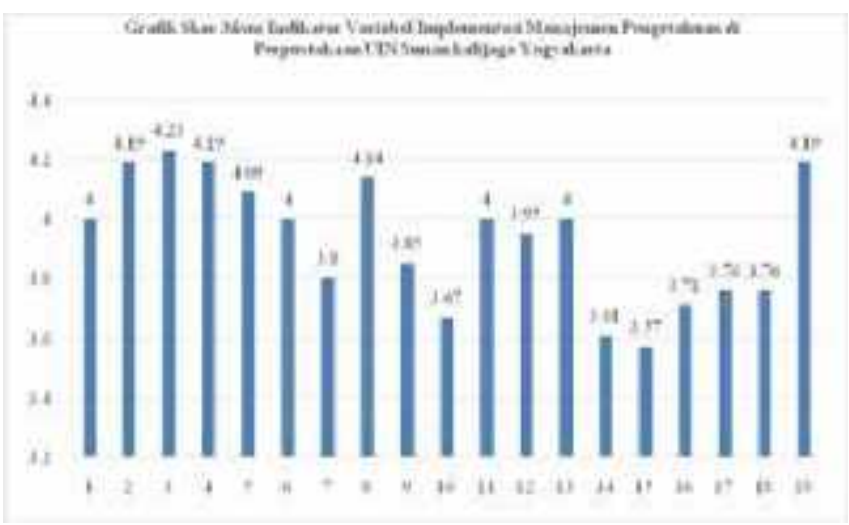

Grafik 1. Skor Mean Indikator Variabel Implementasi Manajemen Pengetahuan

di Perpustakaan UIN Sunan Kalijaga Yogyakarta

Sumber: Analisis Hasil Lapangan

Pada 19 butir pernyataan yang berkaitan dengan implementasi manajemen pengetahuan, diketahui bahwa skor tertinggi terdapat pada indikator Leadership, khusunya pernyataan pimpinan, "Saya menyadari bahwa berbagi pengetahuan adalah hal yang penting" yang memperoleh skor 4,238 (sangat tinggi). Namun, terdapat juga beberapa kondisi yang mendapatkan skor di bawah rata-rata $(3,958)$, yaitu:

1) kemampuan untuk mengoperasikan teknologi informasi yang bisa digunakan untuk berkomunikasi dan berbagi pengetahuan antar pustakawan (3,809); 2) Kemampuan untuk memanfaatkan grup media sosial untuk memudahkan berdiskusi dengan pustakawan yang lain $(3,857)$; 3) Kemampuan untuk memanfaatkan instant messenger untuk memudahkan berdiskusi dengan pustakawan yang lain $(3,666) ; 4)$ kesadaran institusi untuk mengikuti tren dan perkembangan positif yang ada di dunia perpustakaan (3,952); 5) Adanya penghargaan yang diberikan institusi kepada pustakawan yang berprestasi (3,952); 6) Penyelesaian masalah yang ada di institusi diselesaikan secara sistematis, yaitu dengan melibatkan seluruh pustakawan $(3,571)$; 7) Institusi tidak ragu-ragu untuk mencoba penyelesaian masalah dengan metode yang baru $(3,714)$; 8) Dalam menyelesaikan masalah, institusi bercermin pada permasalahan yang pernah ada sebelumnya (3,762); 9) Institusi aktif menyelesaikan masalah dengan praktikpraktik terbaik yang pernah dilakukan institusi lain $(3,762)$.

$$
\text { Sedangkan perbandingan tingkat }
$$
implementasi manajemen pengetahuan antara pustakawan yang berlatar belakang pendidikan formal ilmu perpustakaan dan informasi dan nonilmu perpustakaan dan informasi adalah sebagai berikut:

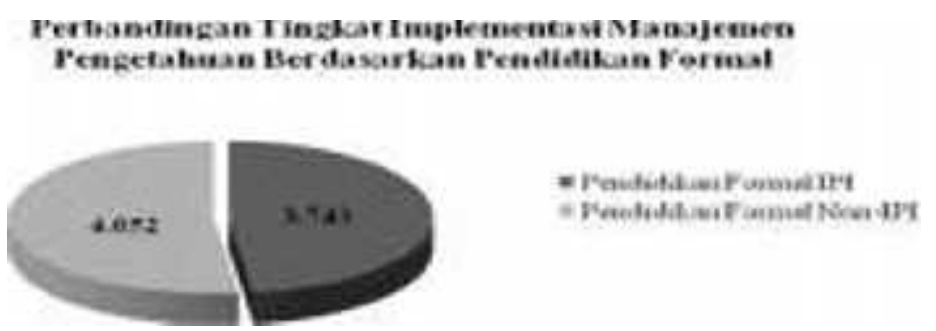

Grafik 2. Perbandingan Tingkat Implementasi Manajemen Pengetahuan Pustakawan

Berdasarkan Latar Belakang Pendidikan Formal Sumber: Analisis Hasil Lapangan

Dari gambar tersebut maka bisa diketahui bahwa pustakawan yang berlatar belakang pendidikan formal IPI memiliki tingkat implementasi manajemen pengetahuan 3,743 yaitu lebih rendah daripada pustakawan yang berlatar belakang pendidikan formal non-IPI 
yaitu 4,052, meskipun keduanya berada pada tingkat yang sama yaitu berada pada rentang 3,40-4,20 yang berarti mengimplementasikan manajemen pengetahuan dengan cukup tinggi.

Asumsi awal penulis dan observasi di lapangan yang menyatakan bahwa latar belakang pendidikan pustakawan dikhawatirkan menyebabkan gap/jenjang pengetahuan perlu dianalisis lebih lanjut dalam penelitian yang lebih mendalam. Dari hasil analisis data menggunakan mean dan grand mean diketahui bahwa terdapat perbedaan tingkat implementasi manajemen penge- tahuan antara pustakawan yang berlatar belakang pendidikan IPI dan pustakawan yang berlatar belakang pendidikan non-IPI. Faktorfaktor lain yang menyebabkan perbedaan skor tersebut tidak dianalisis lebih lanjut dalam penelitian ini.

\section{SIMPULAN}

1. Implementasi manajemen pengetahuan yang dilakukan oleh pustakawan di Perpustakaan UIN Sunan Kalijaga Yogyakara, memperoleh nilai grand mean 3,958. Nilai tersebut berada pada rentang skala 3,40-4,20 yang menunjukkan bahwa implementasi manajemen pengetahuan yang dilakukan oleh pustakawan di Perpustakaan UIN Sunan Kalijaga Yogyakara berada pada tingkat yang tinggi.

2. Kendala-kendala yang menghambat proses implementasi manajemen pengetahuan, dibuktikan dengan tingginya nilai grand mean

3. Perlunya pustakawan meningkatkan implementasi manajemen pengetahuan, terutama pada aspek-aspek yang memperoleh skor mean rendah. Skor terendah terdapat pada indikator learning, terutama pada pernyataan "Penyelesaian masalah yang ada di institusi diselesaikan secara sistematis, yaitu dengan melibatkan seluruh pustakawan" pernyataan tersebut mendapatkan skor mean terendah yaitu sebesar 3,571. Skor tersebut masih di bawah skor grand mean

$$
\text { 4. Pustakawan perlu meningkatkan }
$$

koordinasi agar penyelesaian masalah dilakukan secara sistematis serta melibatkan seluruh pustakawan. Meskipun demikian analisis dalam pene- litian yang kuantitatif ini tentu tidak bisa menjelaskan fenomena di lapangan secara mendalam. Diharapkan penelitian ini mampu menjadi rujukan untuk melakukan penelitian yang berkaitan dengan manajemen pengetahuan dengan analisis dan pembahasan yang lebih mendalam.

\section{DAFTAR PUSTAKA}

\section{Akli, Z. (2012). Orasi Ilmiah Pengukuhan} Pustakawan Utama Perpustakaan Nasional RI: Strategi Pemberdayaan Pustakawan dalam Mewujudkan Layanan Prima di Perpustakaan. Jakarta: Perpustakaan Nasional Republik Indonesia.

Aldi, B. E. (2005). Menjadikan Manajemen Pengetahuan Sebagai Keunggulan Kompetitif Perusahaan Melalui Strategi Berbasis Pengetahuan. Jurnal Studi Manajemen dan Organisasi, 58-68.

Basuki, S. (1991). Pengantar Ilmu Perpustakaan. Jakarta: Gramedia Pustaka Utama.

Hadna, I. N. (2014). Guide Book Perpustakaan UIN Sunan Kalijaga Yogyakarta. Yogyakarta: Perpustakaan UIN Sunan Kalijaga.

Kurniawati, S. (2012). Model Penerapan Knowledge Management pada BUMN Penyelenggara Bisnis Jasa Komunikasi. Jurnal Pendidikan Ekonomi dan Koperasi, 285-300. 
Lumbantobing, P. (2011). Manajemen Knowledge

Sharing Berbasis Komunitas. Bandung:

Knowledge Management Society

Indonesia.

Purwono. (2013). Profesi Pustakawan

Menghadapi Tantangan Perubahan.

Yogyakarta: Graha Ilmu.

Qalyubi, S. (2007). Dasar-Dasar Ilmu

Perpustakaan dan Informasi. Yogyakarta:

UIN Sunan Kalijaga.

Ralph, L. L. (2008). An Investigation of a Knowledge Management Solution for Reference Services. Florida: Graduate School of Computer and Information Sciences Nova Southeastern University.

Rodin, R. (2013). Penerapan Knowledge Management di Perpustakaan: Studi Kasus di Perpustakaan STAIN Curup. Khizanah Al-Hikmah, 35-46.

Simamora, B. (2008). Panduan Riset Perilaku Konsumen. Jakarta: Gramedia Pustaka Utama.

Suhartika, I. P. (2004). Implementasi Teknologi Informasi Sebagai Usaha Peningkatan Mutu Layanan Perpustakaan. Visi Pustaka, 11-14. 
